\title{
A Tractable Method to Measure Utility and Loss Aversion under Prospect Theory
}

\author{
Mohammed Abdellaoui \\ CNRS-GRID, ESTP \& ENSAM, 30 Avenue du Président Wilson, 94230 Cachan, France, \\ abdellaoui@grid.ensam.estp.fr. \\ Han Bleichrodt \\ Dept. of Economics, Erasmus University, PO Box 1738, 3000 DR Rotterdam, the Netherlands, \\ bleichrodt@few.eur.nl. \\ Olivier L'Haridon \\ GRID, ESTP \& ENSAM, 30 Avenue du Président Wilson, 94230 Cachan, France, lharidon@grid.ensam.estp.fr
}

April 2007 


\begin{abstract}
This paper provides an efficient method to measure utility under prospect theory, the most important descriptive theory of decision under uncertainty today. Our method is based on the elicitation of certainty equivalents for two-outcome prospects, a common way to measure utility. We applied our method in an experiment and found that most subjects were risk averse for gains and risk seeking for losses but had concave utility both for gains and for losses. This finding illustrates empirically that risk seeking and concave utility can coincide under prospect theory, a result that was derived theoretically by Chateauneuf and Cohen (1994). Utility was steeper for losses than for gains, which is consistent with loss aversion. Utility did not depend on the probability used in the elicitation, which offers support for prospect theory.
\end{abstract}

Key words: Prospect theory, utility measurement, loss aversion. 


\section{Introduction}

Traditionally, utility measurement has assumed that people behave according to expected utility. Then a decision maker's utility can be measured by eliciting a few equivalences between prospects. Evidence abounds, however, that people violate expected utility in systematic ways (Starmer 2000) and that utility measurements based on expected utility give inconsistent results (Hershey and Schoemaker 1985, Bleichrodt, Pinto, and Wakker 2001, Abdellaoui, Barrios, and Wakker 2007). An obvious danger of basing utility measurement on a theory that is descriptively invalid is that the obtained utilities will be biased and that recommendations are made that are not in the decision maker's best interests.

Two important causes of violations of expected utility are probability weighting, the nonlinear evaluation of probabilities, and loss aversion, the finding that people evaluate outcomes as gains and losses relative to a reference point and are more sensitive to losses than to gains. Both probability weighting and loss aversion are modeled by prospect theory, currently the most influential descriptive model of decision under risk. A difficulty in measuring utility under prospect theory is that the methods that are commonly used to measure utility, such as the probability, certainty equivalence, and lottery equivalence methods (Farquhar 1984, McCord and de Neufville 1986) are no longer valid because they do not take account of probability weighting and loss aversion. Wakker and Deneffe's (1996) trade-off method is robust to probability weighting when all outcomes are of the same sign, but is not able to handle loss aversion.

The main problem in measuring utility under prospect theory is the presence of probability weighting, in particular the possibility that probability weighting can be different for gains and losses. Several studies solved this problem by assuming parametric forms for probability weighting (Tversky and Kahneman 1992, Booij and van de Kuilen 2006). Abdellaoui, Bleichrodt, and Paraschiv (forthcoming) derived a nonparametric method to 
completely measure utility under prospect theory, i.e. their method imposed no assumptions on utility, probability weighting, and loss aversion. Nonparametric measurements offer three important advantages over parametric measurements. First, the measurements are not confounded by assumptions about the shape of utility or probability weighting. Second, the measurements provide insight in the psychological processes underlying the measurements because there is a direct link between choices and utilities. Third, the direct link between choices and utilities allows solving inconsistencies in utility measurement, which is important for prescriptive decision making. Observed inconsistencies can be directly related to particular choices and solving these inconsistencies will give new insights into the decision maker's preferences. Under parametric assumptions there is no direct link between choices and utilities. A drawback of nonparametric measurements is that they are generally less efficient, in the sense that more questions are needed to elicit utility, and more susceptible to response error than parametric measurements.

The purpose of this paper is to propose a new method to measure utility under prospect theory that seeks to achieve a balance between the advantages of nonparametric and parametric measurements. The key insight behind our method is that only the decision weight of one probability needs to be known to measure utility. This insight reduces the number of measurements and thereby enhances the scope for application of prospect theory in empirical research and practical decision making. Because we only need the weight of one probability our method requires no assumptions about probability weighting. The method is based on the elicitation of certainty equivalents of prospects involving just two outcomes, a widely used method in applied research. The different certainty equivalents are not linked and, hence, not susceptible to error propagation. For utility, we adopt a parametric specification, the power function. Our decision to select a parametric specification for utility is based on previous 
findings that the power function provides an excellent fit to utility measurements (for an overview see Stott 2006).

We applied our method in an experiment and found concave utility both on the gains domain and on the loss domain. There was clear evidence of loss aversion both at the individual and at the aggregate level. Even though we observed concave utility for losses, most of our subjects were risk seeking for losses. This observation shows that the one-to-one relationship between risk aversion and utility curvature that exists under expected utility no longer holds under prospect theory. Chateauneuf and Cohen (1994, Corollary 4) derived theoretically that risk seeking behavior and concave utility can coincide under prospect theory. Our finding can be interpreted as the empirical counterpart to Chateuneuf and Cohen (1994).

The paper proceeds as follows. Section 2 reviews prospect theory and previous empirical evidence on utility, probability weighting and loss aversion under prospect theory. Section 3 describes our method for eliciting prospect theory. Section 4 describes the design of an experiment in which our method was applied. Section 5 describes the results of our experiment and Section 6 concludes.

\section{Prospect Theory}

We consider a decision maker who has to make a choice between risky prospects. Because we will only use prospects with at most two distinct outcomes, we restrict the discussion to such prospects. On the domain of two-outcome prospects original prospect

theory (Kahneman and Tversky 1979) and new (or cumulative) prospect theory (Tversky and Kahneman 1992) coincide, and hence our derivations and estimations are valid for both theories.

We write $(\mathrm{x}, \mathrm{p} ; \mathrm{y})$ for the prospect that results in outcome $\mathrm{x}$ with probability $\mathrm{p}$ and in outcome y with probability $1-\mathrm{p}$. The individual has preferences over prospects and we use 
the conventional notation $>$, $\succcurlyeq$, and $\sim$ to represent the relations of strict preference, weak preference, and indifference. Outcomes are real numbers, they are money amounts in the experiment eported in Section 4. Higher numbers are always preferred. If $\mathrm{x}=\mathrm{y}$ or $\mathrm{p}=0$ or $\mathrm{p}$ $=1$ the prospect is riskless, otherwise it is risky. Outcomes are expressed as changes with respect to the status quo or reference point, i.e. as gains or losses. Throughout the paper, we assume that the reference point is 0 . Hence, gains are outcomes larger than 0 and losses outcomes less than 0. A mixed prospect involves both a gain and a loss; otherwise the prospect is non-mixed. For notational convenience, we assume that all prospects $(\mathrm{x}, \mathrm{p} ; \mathrm{y})$ are rank-ordered. If a non-mixed prospect involves only gains [losses], we assume that $\mathrm{x} \geq \mathrm{y} \geq 0$ $[\mathrm{x} \leq \mathrm{y} \leq 0]$. For mixed prospects we assume that $\mathrm{x}>0>\mathrm{y}$.

\section{Utility and probability weighting for gains and losses}

The individual evaluates each prospect and chooses the prospect that offers the highest overall utility. The overall utility of a prospect is expressed in terms of three functions: a probability weighting function $\mathrm{w}^{+}$for gains, a probability weighting function $\mathrm{w}^{-}$ for losses, and a utility function $\mathrm{U}$. The functions $\mathrm{w}^{+}$and $\mathrm{w}^{-}$assign a probability weight to each probability. They are strictly increasing and satisfy $\mathrm{w}^{+}(0)=\mathrm{w}^{-}(0)=0$ and $\mathrm{w}^{+}(1)=\mathrm{w}^{-}(1)$ $=1$. The utility function $\mathrm{U}$ assigns a real number to each outcome, which reflects the desirability of that outcome. The function $U$ is strictly increasing and satisfies $U(0)=0$. $U$ is a ratio scale, i.e. we can arbitrarily choose the unit of the function.

The evaluation of a prospect depends amongst other things on the sign of the outcomes. If the prospect $(x, p ; y)$ is non-mixed then its utility is

$$
\mathrm{w}^{\mathrm{s}}(\mathrm{p})(\mathrm{U}(\mathrm{x})-\mathrm{U}(\mathrm{y}))+\mathrm{U}(\mathrm{y})
$$


where $\mathrm{s}=+$ for gains and $\mathrm{s}=-$ for losses. The intuition behind (1) is that the decision maker gains [loses] at least $\mathrm{U}(\mathrm{y})$, regardless of how the uncertainty is resolved, and may gain [lose] an additional $\mathrm{w}^{\mathrm{s}}(\mathrm{p})(\mathrm{U}(\mathrm{x})-\mathrm{U}(\mathrm{y}))$. If the prospect $(\mathrm{x}, \mathrm{p} ; \mathrm{y})$ is mixed then its utility is

$$
\mathrm{w}^{+}(\mathrm{p}) \mathrm{U}(\mathrm{x})+\mathrm{w}^{-}(1-\mathrm{p}) \mathrm{U}(\mathrm{y})
$$

Expected utility concerns the special case of (1) and (2) where $\mathrm{w}^{+}(\mathrm{p})=\mathrm{w}^{-}(\mathrm{p})=\mathrm{p}$.

Kahneman and Tversky (1979) assumed that the probability weighting functions $\mathrm{w}^{+}$ and $\mathrm{w}^{-}$overweight small probabilities and underweight moderate and high probabilities, giving rise to an inverse S-shaped probability weighting function. The utility function is assumed to be concave for gains and convex for losses, implying an S-shaped utility function, and steeper for losses than for gains. The combination of these assumptions entails a fourfold pattern of risk attitudes: risk aversion for small-p losses and larger-p gains and risk seeking for larger-p losses and small-p gains. Loss aversion implies strong risk aversion for mixed prospects. Empirical evidence supports these predictions (e.g. Laughhunn, Payne, and Crum 1980; Payne, Laughhunn, and Crum 1980, 1981; Schoemaker 1990; Myagkov and Plott 1997; Heath, Huddart, and Lang 1999).

Most empirical studies on probability weighting observed inverse S-shaped probability weighting both for gains and for losses (Tversky and Kahneman 1992; Tversky and Fox 1995; Wu and Gonzalez 1996; Gonzalez and Wu 1999; Abdellaoui 2000; Bleichrodt and Pinto 2000). The point where the probability weighting changes from overweighting probabilities to underweighting probabilities lies around $1 / 3$. Tests of functional forms for the probability weighting function have produced equivocal results. After adjusting for degrees of freedom, Gonzalez and Wu (1999), Bleichrodt and Pinto (2000), and Sneddon and Luce (2001) observed that two-parameter forms fitted better than single-parameter forms. Wu and 
Gonzalez (1996) and Stott (2006) on the other hand found that the single-parameter models performed at least as good as the two-parameter models.

Measurements of the shape of utility for gains and for losses have generally confirmed prospect theory's assumption of concave utility for gains and convex utility for losses. The available evidence is stronger for gains than for losses. Tversky and Kahneman (1992) assumed power utility and found a median power coefficient of 0.88 both for gains and for losses. These estimates are consistent with an S-shaped utility function. A disadvantage of Tversky and Kahneman's estimation is that they had to assume a parametric form for probability weighting. Gonzalez and $\mathrm{Wu}(1999)$ found that this specification was rejected for most of their subjects. Camerer and Ho (1994), Wu and Gonzalez (1996), and Stott (2006) also adopted parametric forms but only estimated the utility for gains. Their results were consistent with concave utility for gains.

Baucells and Heukamp (2006) performed a test of prospect theory based on stochastic dominance relations and found support for an S-shaped utility function. Their method also required prior qualitative assumptions about probability weighting.

Several studies have used Wakker and Deneffe's (1996) trade-off method to perform separate measurements of the utility for gains and the utility for losses and, hence, their findings were not affected by probability weighting. Fennema and van Assen (1998), Abdellaoui (2000), Abdellaoui, Vossmann, and Weber (2005), Schunk and Betsch (2006), and Abdellaoui, Barrios, and Wakker (2007) found that the utility for gains was concave both at the aggregate level (median power coefficients were generally between 0.77 and 0.91 with the exception of Fennema and van Assen (1998) who obtained median power coefficients of 0.21 and 0.39 ) and for the majority of their subjects. Empirical support for convex utility for losses was weaker. Fennema and van Assen (1998), Abdellaoui (2000), Etchart-Vincent (2004), Abdellaoui, Vossmann, and Weber (2005), and Schunk and Betsch (2006) found 
slightly convex utility for losses at the aggregate level (median power coefficients varied between 0.84 and 0.97 ). At the individual level, the most common pattern was convex utility for losses (between $24 \%$ and $47 \%$ of the subjects), but concave and linear utility functions were also common.

Abdellaoui, Bleichrodt, and Paraschiv (forthcoming) estimated the utility for gains and losses simultaneously, i.e. they performed a complete elicitation of utility under prospect theory, and did not make any assumptions about utility or probability weighting. They found strong support for the S-shaped utility function both at the aggregate and at the individual level. For their median data, the power estimates were 0.72 for gains and 0.73 for losses. Seventy percent of their subjects had concave utility for gains and also $70 \%$ had convex utility for losses. Fifty-four percent had an S-shaped utility function. Recently, Booij and van de Kuilen (2006) proposed another method to measure the utility for gains and losses simultaneously. They also found support for S-shaped utility, with mean power coefficients of 0.94 for gains and 0.90 to 0.93 for losses. The method of Booij and van de Kuilen (2006) does not estimate probability weighting but, instead, specific assumptions about probability weighting have to be imposed. They assumed that probability weighting could be modeled by the one-parameter form of Tversky and Kahneman (1992) and imposed the median parameter obtained by Tversky and Kahneman (1992) on all of their subjects. Hence, they did not allow for individual heterogeneity in probability weighting.

\section{Loss aversion}

Many empirical studies have observed qualitative support for loss aversion. Few studies have, however, performed quantitative estimations of loss aversions. To measure loss aversion the utility for gains and losses must be measured simultaneously and, as mentioned before, until recently no method existed to perform such a measurement without imposing 
additional assumptions. An additional complication in the measurement of loss aversion is that there is no agreed-upon definition of loss aversion. Kahneman and Tversky (1979) suggested that loss aversion be defined by $-U(-x)>U(x)$ for all $x>0$. This implies that a loss aversion coefficient can be defined as the mean or median of $-\frac{\mathrm{U}(-\mathrm{x})}{\mathrm{U}(\mathrm{x})}$ over relevant $\mathrm{x}$. Tversky and Kahneman (1992) implicitly used $-\frac{\mathrm{U}(-\$ 1)}{\mathrm{U}(\$ 1)}$ as an index of loss aversion. Köbberling and Wakker (2005) defined the loss aversion coefficient as, $\frac{U_{\uparrow}^{\prime}(0)}{U_{\downarrow}^{\prime}(0)}$ where $U_{\uparrow}^{\prime}(0)$ stands for the left and $U_{\downarrow}^{\prime}(0)$ for the right derivative of $U$ at the reference point. This definition can be considered the limiting case of Kahneman and Tversky's (1979) definition for x approaching 0. A similar definition was suggested by Benartzi and Thaler (1995). Wakker and Tversky (1993) used a stronger definition of loss aversion and required that $\mathrm{U}^{\prime}(-\mathrm{x}) \geq \mathrm{U}^{\prime}(\mathrm{x})$ for all $\mathrm{x}>0$, i.e. the slope of the utility function at each loss is at least as large as the slope of the utility function at the absolutely commensurate gain. Their definition could be related to a loss aversion coefficient of the mean or median of $\frac{U^{\prime}(-x)}{U^{\prime}(x)}$. Neilson (2002) and Bowman, Minehart, and Rabin (1999) proposed other definitions but these are difficult to apply empirically as was shown by Abdellaoui, Bleichrodt, and Paraschiv (forthcoming). Schmidt and Zank (2005) proposed a behavioral definition of loss aversion, which is equivalent to the definition of Kahneman and Tversky (1979) on the domain of prospects considered in this paper.

Table 1 gives an overview of the studies that estimated a loss aversion coefficient. Bleichrodt, Pinto, and Wakker (2001) estimated two loss aversion coefficients using different datasets. Bleichrodt et al. (2007) estimated six loss aversion coefficients. Booij and van de Kuilen (2006) estimated separate loss aversion coefficients for high and low monetary 
amounts. Except for Abdellaoui, Bleichrodt, and Paraschiv (forthcoming), all studies adopted parametric assumptions about utility and probability weighting, but the assumptions that were adopted differed across studies. Besides, different definitions of loss aversion were used. The estimated values for the coefficient of loss aversion vary, but are hard to compare because of the different assumptions and definitions used and because some studies reported median values and the others mean values.

Table 1: Estimates of the Loss Aversion Coefficient

\begin{tabular}{|c|c|c|c|}
\hline Study & Definition & Domain & Estimates \\
\hline Fishburn and Kochenberger (1979) & $\frac{\mathrm{U}^{\prime}(-\mathrm{x})}{\mathrm{U}^{\prime}(\mathrm{x})}$ & Money & 4.8 \\
\hline Tversky and Kahneman (1992) & $\frac{-\mathrm{U}(-1)}{\mathrm{U}(1)}$ & Money & 2.25 \\
\hline Bleichrodt, Pinto, and Wakker (2001) & $\frac{-\mathrm{U}(-\mathrm{x})}{\mathrm{U}(\mathrm{x})}$ & Health & $\begin{array}{l}2.17 \\
3.06 \\
\end{array}$ \\
\hline Schmidt and Traub (2002) & $\frac{\mathrm{U}^{\prime}(-\mathrm{x})}{\mathrm{U}^{\prime}(\mathrm{x})}$ & Money & $1.43^{*}$ \\
\hline Pennings and Smidts (2003) & $\frac{\mathrm{U}^{\prime}(-\mathrm{x})}{\mathrm{U}^{\prime}(\mathrm{x})}$ & Money & $1.81^{*}$ \\
\hline Bleichrodt et al. (2007) & $\frac{-\mathrm{U}(-\mathrm{x})}{\mathrm{U}(\mathrm{x})}$ & Health & $1.53-2.13$ \\
\hline \multirow{4}{*}{$\begin{array}{l}\text { Abdellaoui, Bleichrodt, and Paraschiv. } \\
\text { (forthcoming) }\end{array}$} & $\frac{-\mathrm{U}(-\mathrm{x})}{\mathrm{U}(\mathrm{x})}$ & \multirow{4}{*}{ Money } & $\begin{array}{l}1.72 \\
2.15^{*} \\
\end{array}$ \\
\hline & $\frac{\mathrm{U}^{\prime}(-\mathrm{x})}{\mathrm{U}^{\prime}(\mathrm{x})}$ & & $\begin{array}{l}1.53 \\
2.02^{*} \\
\end{array}$ \\
\hline & $\mathrm{U}_{\uparrow}^{\prime}(0)$ & & 2.52 \\
\hline & $\overline{U_{\downarrow}^{\prime}(0)}$ & & $4.99^{*}$ \\
\hline Booij and van de Kuilen (2006) & $\frac{\mathrm{U}_{\uparrow}^{\prime}(0)}{\mathrm{U}_{\downarrow}^{\prime}(0)}$ & Money & $\begin{array}{l}1.79^{*} \\
1.74^{*}\end{array}$ \\
\hline
\end{tabular}

* denotes a mean value. Otherwise it is a median value.

The estimates in Table 1 are based on aggregate data. Abdellaoui, Bleichrodt, and Paraschiv (forthcoming) also studied loss aversion at the individual level and found that a large majority of their subjects behaved according to loss aversion under the definitions of Kahneman and Tversky (1979), Wakker and Tversky (1993), and Köbberling and Wakker 
(2005). In contrast, Schmidt and Traub (2002), who used the definition of Wakker and Tversky (1993), found that only 33\% of their subjects were loss averse.

\section{Elicitation Method}

Our elicitation method consists of three stages. In the first stage utility is elicited on the gain domain, in the second stage utility is elicited on the loss domain, and in the third stage the utility on the gain domain and on the loss domain are linked. All measurements are based on the elicitation of certainty equivalents for two-outcome prospects. The certainty equivalents of different elicitation questions are not chained. This has the advantage that error propagation does not affect our findings.

Like Köbberling and Wakker (2005), we assume that the observable utility U in prospect theory is a composition of a loss aversion coefficient $\lambda>0$, reflecting the different processing of gains and losses, and a basic utility u that reflects the intrinsic value of outcomes for the agent. This decomposition was also adopted by Tversky and Kahneman (1992), Shalev (2000), and Bleichrodt, Pinto, and Wakker (2001). Formally, this assumption means that

$$
U(x)=\left\{\begin{array}{lll}
u(x) & \text { if } & x \geq 0 \\
\lambda u(x) & \text { if } & x<0
\end{array}\right.
$$

The exact definition of loss aversion depends on the specification of $u$. We will return to this issue later.

\section{Elicitation of utility on the domain of gains and on the domain of losses}

Consider first the elicitation of utility on the gain domain. We start by selecting a probability $\mathrm{p}_{\mathrm{g}}$ that is kept fixed throughout the elicitation of the utility function on the gains 
domain. We choose a series of prospects $\left(x_{i}, p_{g} ; y_{i}\right)$, for which $x_{i}>y_{i} \geq 0, i=1, \ldots, k$. and elicit their certainty equivalents $G_{i}$. By (1) and (3) it follows that

$$
\mathrm{u}\left(\mathrm{G}_{\mathrm{i}}\right)=\delta^{+}\left(\mathrm{u}\left(\mathrm{x}_{\mathrm{i}}\right)-\mathrm{u}\left(\mathrm{y}_{\mathrm{i}}\right)\right)+\mathrm{u}\left(\mathrm{y}_{\mathrm{i}}\right)
$$

or

$$
\mathrm{G}_{\mathrm{i}}=\mathrm{u}^{-1}\left(\delta^{+}\left(\mathrm{u}\left(\mathrm{x}_{\mathrm{i}}\right)-\mathrm{u}\left(\mathrm{y}_{\mathrm{i}}\right)\right)+\mathrm{u}\left(\mathrm{y}_{\mathrm{i}}\right)\right)
$$

where $\delta^{+}=\mathrm{w}^{+}\left(\mathrm{p}_{\mathrm{g}}\right)$. The advantage of keeping the probability $\mathrm{p}_{\mathrm{g}}$ fixed is that only one point of the probability weighting function plays a role in the process of utility elicitation. The probability weight $\delta^{+}$can just be taken to be one additional parameter that has to be estimated in the utility elicitation exercise. In fact, if we adopt a parametric specification for utility, then (5) can easily be estimated through nonlinear least squares. In the experiment described below we adopted the most widely used parametric specification, the power function $\mathrm{u}(\mathrm{x})=$ $\mathrm{x}^{\alpha}$. Then

$$
\mathrm{G}_{\mathrm{i}}=\left(\delta^{+}\left(\mathrm{x}_{\mathrm{i}}^{\alpha}-\mathrm{y}_{\mathrm{i}}^{\alpha}\right)+\mathrm{y}_{\mathrm{i}}^{\alpha}\right)^{1 / \alpha}
$$

where $\alpha$ and $\delta^{+}$are the parameters to be estimated. The parameter $\alpha$ reflects the curvature of the utility function and $\delta^{+}$reflects the impact of probability weighting at probability $\mathrm{p}_{\mathrm{g}}$. Under expected utility we only need to measure $\alpha$. Note that the adoption of a power function implies the scaling $\mathrm{u}(1)=1$. 
Figure 1: The impact of probability weighting on utility measurement

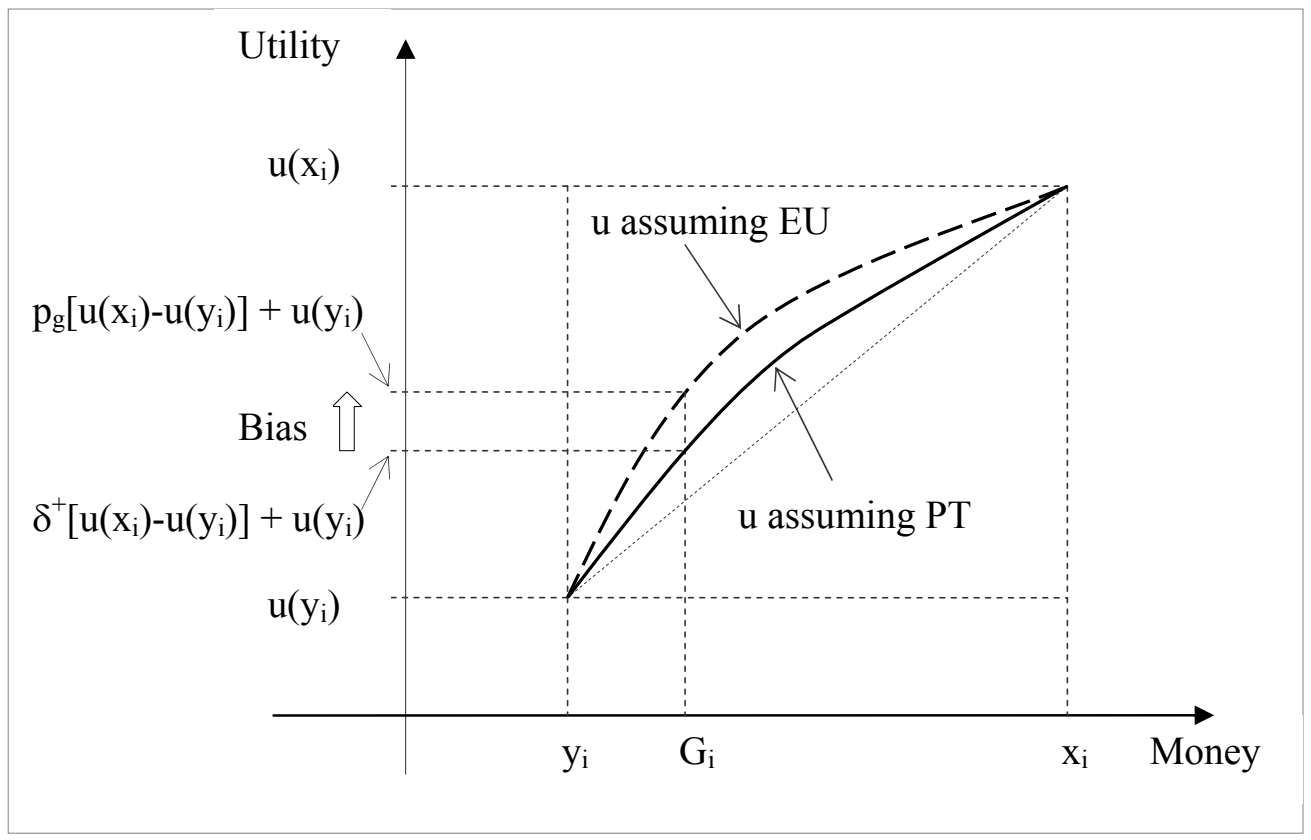

Figure 1 shows the impact of probability weighting on utility measurement when $\delta^{+}<$ $\mathrm{p}_{\mathrm{g}}$, i.e. when probabilities are underweighted. The figure shows that underweighting of probabilities will exert a downward impact on the elicited utilities compared with expected utility, the case in which there is no probability weighting. Because utility is unique up to unit and location we can fix the utility of two outcomes. In the figure, we have fixed the utility of the outcomes $\mathrm{x}_{\mathrm{i}}$ and $\mathrm{y}_{\mathrm{i}}$. Expected utility then posits that the utility of $\mathrm{G}_{\mathrm{i}}$ is equal to $\mathrm{p}_{\mathrm{g}}\left(\mathrm{u}\left(\mathrm{x}_{\mathrm{i}}\right)-\mathrm{u}\left(\mathrm{y}_{\mathrm{i}}\right)\right)+\mathrm{u}\left(\mathrm{y}_{\mathrm{i}}\right)$. This exceeds $\delta^{+}\left(\mathrm{u}\left(\mathrm{x}_{\mathrm{i}}\right)-\mathrm{u}\left(\mathrm{y}_{\mathrm{i}}\right)\right)+\mathrm{u}\left(\mathrm{y}_{\mathrm{i}}\right)$, the utility of $\mathrm{G}_{\mathrm{i}}$ under prospect theory, when probabilities are underweighted. Consequently, analyzing the data under expected utility will overestimate the concavity of utility on the gains domain when probabilities are underweighted. A similar analysis reveals that expected utility will underestimate the concavity of utility on the gains domain when probabilities are overweighted. Figure 1 also shows that if the underweighting of probabilities is strong enough then risk aversion can co-exist with linear or even convex utility. In the figure the 
utility function under expected utility is concave indicating risk aversion. However, if $\delta^{+}$is sufficiently low then the utility function can be convex under prospect theory. Hence, the one-to-one relationship between risk aversion and concave utility, which exists under expected utility, no longer exists under prospect theory. This observation was formally proved by Chateauneuf and Cohen (1994).

The procedure to elicit the utility on the domain of losses is largely similar to the procedure described above for gains. We select $\mathrm{p}_{\ell}=1-\mathrm{p}_{\mathrm{g}}$ and a series of prospects $\left(\mathrm{x}_{\mathrm{i}}, \mathrm{p}_{\ell}, \mathrm{y}_{\mathrm{i}}\right)$ for which $0 \geq y_{i}>x_{i}, i=1, \ldots, k$ and elicit their certainty equivalents $L_{i}$. The reason we set $p_{\ell}=$ $1-p_{g}$ is that this equality is crucial in the estimation of loss aversion. By (1) and (3) it follows that

$$
\mathrm{L}_{\mathrm{i}}=\mathrm{u}^{-1}\left(\delta^{-}\left(\mathrm{u}\left(\mathrm{x}_{\mathrm{i}}\right)-\mathrm{u}\left(\mathrm{y}_{\mathrm{i}}\right)\right)+\mathrm{u}\left(\mathrm{y}_{\mathrm{i}}\right)\right.
$$

where $\delta^{-}=\mathrm{w}^{-}\left(\mathrm{p}_{\ell}\right)$. By adopting a parametric specification for $\mathrm{u}$ we can estimate (7) by nonlinear least squares. Underweighting of probabilities now entails that expected utility will underestimate the concavity of utility on the loss domain and overweighting of probabilities entails that expected utility overestimates the concavity of utility on the loss domain.

Because we only use the weight of one probability we do not have to make assumptions regarding probability weighting in the estimation of (5) and (7). Moreover, (5) and (7) can be estimated at the individual level and, hence, individual heterogeneity in probability weighting is taken into account. 


\section{Measuring loss aversion}

The third stage of our elicitation procedure serves to establish the link between the utility for gains and the utility for losses and, hence, measures the loss aversion coefficient $\lambda$. This can be done through the elicitation of a single indifference. Select a gain $\mathrm{G}^{*}$ from within $\left(0, \mathrm{x}_{\mathrm{k}}\right]$, the interval for which $\mathrm{u}$ was determined in the first stage and determine the loss

$\mathrm{L}^{*}$ for which $\left(\mathrm{G}^{*}, \mathrm{p}_{\mathrm{g}} ; \mathrm{L}^{*}\right) \sim 0$. It follows from (2), (3) and $\mathrm{p}_{\ell}=1-\mathrm{p}_{\mathrm{g}}$ that

$$
\delta^{+} \mathrm{u}\left(\mathrm{G}^{*}\right)+\delta^{-} \lambda \mathrm{u}\left(\mathrm{L}^{*}\right)=\mathrm{u}(0)=0
$$

Because $\delta^{+}, \mathrm{u}\left(\mathrm{G}^{*}\right), \delta^{-}$, and $\mathrm{u}\left(\mathrm{L}^{*}\right)$ are known from the estimation of (5) and (7), (8) uniquely determines $\lambda$.

\section{Experiment}

Subjects

Subjects were 48 (25 female) graduate students in economics and mathematics at the Ecole Normale Supérieure, Antenne de Bretagne, France. They were paid $€ 10$ for their participation. In addition, one subject was randomly selected to play out one of the gain questions with the actual payment divided by 10 . For ethical reasons we could not play out for real one of the loss questions or one of the mixed questions. Several pilot sessions were used to test and fine-tune the experimental design.

\section{Procedure}

The experiment was run on a computer. Responses were collected in personal interview sessions. Subjects were told that there were no right or wrong answers and that they were allowed to take a break at any time during the session. The responses were entered into 
the computer by the interviewer, so that the subjects could focus on the questions. Before the experiment started subjects were given several practice questions. The experiment lasted 60 minutes on average, including 15 minutes for explanation of the tasks and practice questions.

All indifferences were elicited through a series of binary choices. Each binary choice corresponded to an iteration in a bisection process, which is described in Appendix B. After each choice the subject was asked to confirm his choice. We used a choice-based elicitation procedure because previous studies have found that inferring indifferences from a series of choices leads to fewer inconsistencies than asking subjects directly for their indifference values (Bostic, Herrnstein, and Luce 1990). In each choice a subject was faced with two prospects, labeled A and B, where prospect A was always riskless. Prospects were displayed as pie charts with the sizes of the slices of the pie corresponding to the probabilities. Appendix A gives two examples of the way the experimental questions were displayed. To control for response errors, we repeated the first iteration after the final iteration. The iteration process was started anew when a subject changed his choice in the repeat of the first iteration.

\section{Stimuli}

We used 6 certainty equivalence questions to elicit the utility function for gains and 6 certainty equivalence questions to elicit the utility function for losses. The prospects for which we determined the certainty equivalents are displayed in Table 2 . We used substantial money amounts to be able to detect curvature of utility; for small amounts utility is approximately linear (Wakker and Deneffe 1996). We used round money amounts, multiples of $€ 1000$, to facilitate the task for the subjects. As shown by the table, the measurements were not chained and, hence, not vulnerable to error propagation. 
Our method also allows examining the validity of prospect theory with utility equal to (3). As a first test, we elicited the certainty equivalents for two different values of $p_{g}, p_{g}=1 / 2$ and $\mathrm{p}_{\mathrm{g}}=2 / 3$ and, consequently, $\mathrm{p}_{\ell}=1 / 2$ and $\mathrm{p}_{\ell}=1 / 3$ for losses. Under prospect theory we should observe no systematic differences between the utility elicited with $p_{g}=1 / 2$ and the utility elicited with $\mathrm{p}_{\mathrm{g}}=2 / 3$. For losses no difference should be observed between the utility elicited with $\mathrm{p}_{\ell}=1 / 2$ and the utility elicited with $\mathrm{p}_{\ell}=1 / 3$.

Table 2: Questions asked to determine the utility for gains and the utility for losses

\begin{tabular}{|c|c|c|c|c|c|c|}
\hline & \multicolumn{6}{|c|}{ Outcome index $i$} \\
\cline { 2 - 7 } & 1 & 2 & 3 & 4 & 5 & 6 \\
\hline$\left|x_{i}\right|$ & 2000 & 4000 & 6000 & 10000 & 10000 & 10000 \\
\hline$\left|y_{i}\right|$ & 0 & 0 & 0 & 0 & 6000 & 8000 \\
\hline
\end{tabular}

The order in which the 24 certainty equivalents were elicited was random. At the end of the elicitation of the utility for gains and the elicitation for losses we repeated the third iteration for eight questions, four for gains (two for $p_{g}=1 / 2$ and two for $p_{g}=2 / 3$ ) and four for losses (two for $\mathrm{p}_{\ell}=1 / 2$ and two for $\mathrm{p}_{\ell}=1 / 3$ ). The questions that were repeated were determined randomly.

To determine the loss aversion coefficients, we selected $\mathrm{G}_{1}^{*}, \ldots, \mathrm{G}_{6}^{*}$ and determined $\mathrm{L}_{\mathrm{j}}^{*}$ such that $\left(\mathrm{G}_{\mathrm{j}}^{*}, 1 / 2 ; \mathrm{L}_{\mathrm{j}}^{*}\right) \sim 0, \mathrm{j}=1, \ldots, 6$. Our method only needs one indifference to elicit the loss aversion coefficient $\lambda$. We used 6 questions to have another test of the validity of prospect theory with (3). Under prospect theory with (3), the 6 values of the loss aversion coefficients that we observed should be equal. The order in which these questions were asked was random. We repeated the third iteration of two randomly determined questions to test for consistency. 
Analysis

As mentioned before, we used a power specification for utility. To test the robustness of our findings we also explored two other parametric specifications: exponential, and expopower. The power and exponential specification are widely used in economics and decision analysis. The expo-power family was proposed by Abdellaoui, Barrios, and Wakker (2007). The goodness of fit, as measured by the sum of squared errors, did not differ significantly between the three families $(p=0.100)$. Convergence of the estimations was better for power and expo-power than for exponential. The results based on expo and expo-power were similar to the results for the power family. The results were also similar when we took for each subject the family that best fitted his data.

The power family for gains is defined by $\mathrm{x}^{\alpha}$ and for losses by $-(-\mathrm{x})^{\beta}$ with $\alpha, \beta>0$. For gains (losses), the power function is concave if $\alpha<1(\beta<1)$, linear if $\alpha=1(\beta=1)$, and convex if $\alpha>1(\beta>1)$. For the power family the loss aversion coefficient $\lambda$ is defined as $\frac{-\mathrm{U}(-1)}{\mathrm{U}(1)}$. This is the definition implicitly adopted by Tversky and Kahneman (1992). Given the stakes used in the experiment, this definition is also close to the definition of Köbbering and Wakker (2005) in our study.

Based on the obtained estimates for the power coefficient we could classify individuals according to the shape of their utility for gains and the shape of their utility for losses. We used two classifications. In the first classification, a subject was classified as concave (convex) for gains if the power estimate for gains was less than (greater than) 1. For losses a subject was classified as convex (concave) if the power estimate for losses was less than (greater than) 1. In the second classification, which was included to examine the robustness of the first classification, we only counted the number of subjects for whom the power coefficient differed statistically significantly from 1 based on the standard error that 
resulted from the nonlinear least squares estimation. This second classification led to similar conclusions as the first and, hence, these data are not reported separately.

In each question, a subject was risk averse if the certainty equivalent was less than the expected value of the prospect, risk neutral if the certainty equivalent was equal to the expected value of the prospect, and risk seeking if the certainty equivalent exceeded the expected value of the prospect. To account for response error, we classified a subject as risk averse for gains (losses) if at least 8 out of 12 certainty equivalence questions involving gains (losses) produced a risk averse answer. Similarly, a subject was classified as risk neutral (seeking) if at least 8 out of 12 questions produced a risk neutral (seeking) answer.

For loss aversion we computed for each subject the median of the six elicited loss aversion coefficients. A subject was classified as loss averse if this median exceeded 1 and as gain seeking if it was less than 1 .

We will focus on the medians in what follows. The results for the means were similar. Significance of differences was tested by the Wilcoxon test and by the Friedman test (for comparisons between more than two variables). The binomial test was used to test for differences between proportions.

\section{Results}

\section{Reliability}

One subject was excluded because she did not understand the task. This left 47 subjects in the final analysis. In the analysis of loss aversion we excluded another five subjects because they were not willing to trade any loss for a gain regardless how small the loss.

The reliability of the responses was good. In $95.6 \%$ of the cases, the replication of the first iteration led to the same choice as the first iteration. In $66 \%$ of the cases, the replication 
of the third iteration led to the same choice. The lower reliability in the third iteration is not surprising because the stimulus value was generally close to the certainty equivalent in the third iteration. The reliability in the repeat of the third iteration was comparable to the reliability observed in previous studies (for an overview see Table 1 in Stott (2006). In the repeat of the first iteration the reliability was much better, which is not surprising given that these involved choices for which most subjects had a clear preference for one of the two options.

\section{Consistency}

The consistency tests supported prospect theory. We neither observed significant differences between the utility for gains elicited using $p_{g}=1 / 2$ and the utility for gains elicited using $p_{g}=2 / 3(p=0.492)$ nor between the utility for losses elicited using $p_{\ell}=1 / 2$ and the utility for losses elicited using $\mathrm{p}_{\ell}=1 / 3(\mathrm{p}=0.320)$. Because utility did not depend on the probability used in the elicitation, we will mainly focus on the results for $\mathrm{p}_{\mathrm{g}}=\mathrm{p}_{\ell}=1 / 2$ in what follows.

Table 3: Elicited loss aversion coefficients from the 6 mixed prospects.

\begin{tabular}{lcccccc}
\hline & G1 & G2 & G3 & G4 & G5 & G6 \\
Median & 2.24 & 2.50 & 2.77 & 2.86 & 2.54 & 3.01 \\
IQR & $1.12-7.27$ & $1.36-4.23$ & $1.48-6.51$ & $1.41-6.30$ & $1.71-3.58$ & $1.23-6.39$ \\
\hline
\end{tabular}

IQR stands for interquartile range

Table 3 shows the median loss aversion coefficients elicited from the six mixed prospects. Although there is some variation in the medians, we could not reject the null hypothesis that the 6 elicited loss aversion coefficients were equal. This is consistent with prospect theory and (3) and we will henceforth pool the observations from the six loss aversion questions. 
Table 4: Median elicited certainty equivalents (absolute values).

\begin{tabular}{|c|c|c|c|c|}
\hline \multirow{2}{*}{ Question } & \multicolumn{2}{|c|}{ Gains } & \multicolumn{2}{c|}{ Losses } \\
\cline { 2 - 5 } & $\mathrm{p}_{\mathrm{g}}=1 / 2$ & $\mathrm{p}_{\mathrm{g}}=2 / 3$ & $\mathrm{p}_{\ell}=1 / 3$ & $\mathrm{p}_{\ell}=1 / 2$ \\
\hline 1 & 900 & 1115 & 590 & 900 \\
& $(697-900)$ & $(780-1200)$ & $(550-860)$ & $(840-1090)$ \\
\hline 2 & 1810 & 2235 & 1575 & 2185 \\
& $(1310-1810)$ & $(1740-2405)$ & $(860-2110)$ & $(1810-2185)$ \\
\hline 3 & 2525 & 2625 & 1810 & 3275 \\
& $(1965-2715)$ & $(1625-3375)$ & $(1685-2625)$ & $(2105-4025)$ \\
\hline 4 & 4215 & 4365 & 3950 & 4525 \\
& $(2260-4525)$ & $(3950-6030)$ & $(2175-4365)$ & $(4215-5775)$ \\
\hline 5 & 7810 & 8235 & 7200 & 7810 \\
& $(7210-8185)$ & $(7575-8780)$ & $(7115-7575)$ & $(7685-8185)$ \\
\hline 6 & 8900 & 9115 & 8780 & 8900 \\
& $(8690-9090)$ & $(8860-9200)$ & $(8530-9050)$ & $(8840-9040)$ \\
\hline
\end{tabular}

Interquartile ranges are in parentheses.

Median certainty equivalents and risk attitude

Table 4 shows the median responses to the 24 certainty equivalence questions used to elicit the utility for gains and the utility for losses and their interquartile ranges. The table shows that the dominant pattern is risk aversion for gains and risk seeking for losses, but for losses subjects were closer to being risk neutral than for gains. For gains, the certainty equivalent of a prospect is always lower than its expected value, consistent with risk aversion. Overall, $74 \%$ of the choices were consistent with risk aversion for $\mathrm{p}_{\mathrm{g}}=1 / 2$ and $81 \%$ for $\mathrm{p}_{\mathrm{g}}=$ $2 / 3$. For losses and $\mathrm{p}_{\ell}=1 / 2$, there is risk seeking in each question (the expected value is smaller than the certainty equivalent). For $\mathrm{p}_{\ell}=1 / 3$, there is risk seeking in 3 questions and risk aversion in the other 3 . Overall, $59 \%$ of the choices were consistent with risk seeking for $\mathrm{p}_{\ell}=$ $1 / 2$, but only $46 \%$ for $\mathrm{p}_{\ell}=1 / 3$. The difference between the certainty equivalent and the expected value is generally larger for gains than for losses. 
Table 5: Classification of subjects in terms of risk attitude

\begin{tabular}{|l|l|c|c|c|c|}
\hline & \multicolumn{5}{|c|}{ Losses } \\
\hline \multirow{3}{*}{ Gains } & & Risk averse & Risk seeking & Mixed & Total \\
\cline { 2 - 6 } & Risk averse & 15 & 10 & 10 & 35 \\
\cline { 2 - 6 } & Risk seeking & 0 & 3 & 0 & 3 \\
\cline { 2 - 6 } & Mixed & 1 & 7 & 1 & 9 \\
\cline { 2 - 6 } & Total & 16 & 20 & 11 & 47 \\
\hline
\end{tabular}

Table 5 shows the classification of the subjects in terms of their risk attitude for gains and for losses. Risk aversion was dominant for gains, the difference between risk averse and risk seeking was highly significant $(\mathrm{p}<0.001)$. The proportion of risk averse subjects that we observed was comparable to the proportion observed in previous studies (Schoemaker 1990; Tversky and Kahneman 1992; Fennema and van Assen 1998; Abdellaoui 2000; Abdellaoui, Bleichrodt, and Paraschiv forthcoming; Baucells and Villasis 2006). For losses the picture was more varied. Risk seeking was most common but the difference between the proportion of risk seeking subjects and the proportion of risk averse subjects was not significant $(\mathrm{p}=$ 0.617). The proportion of risk seeking subjects that we observed was generally lower than in previous studies, the exception being Booij and van de Kuilen (2006). When we combine risk attitudes for gains and for losses, the most common pattern is risk aversion both for gains and for losses. The proportion of subjects who were risk averse both for gains and for losses was, however, not significantly different from the proportion of subjects who were risk averse for gains and risk seeking for losses $(\mathrm{p}=0.424)$ and was considerably lower than the proportion observed in previous studies, except for Booij and van de Kuilen (2006).

Consistent with previous studies we observed strong risk aversion in the mixed prospects. Table 6 shows the median results in the mixed prospects. The size of the loss that established indifference was typically around half the size of the corresponding gain. Overall, $80.5 \%$ of choices were risk averse. At the individual level, the degree of risk aversion was 
comparable to the degree of risk aversion in the pure gains prospects: 36 subjects were risk averse, 9 risk seeking, and 2 were classified as mixed.

Table 6: Median Results in the Mixed Prospects.

\begin{tabular}{|c|c|c|}
\hline Question & $\mathrm{G}_{\mathrm{j}}^{*}$ & $\mathrm{~L}_{\mathrm{j}}^{*}$ \\
\hline 1 & 900 & 515 \\
$(697-900)$ & $(313-910)$ \\
\hline 2 & 1810 & 980 \\
$(1310-1810)$ & $(532-1528)$ \\
\hline 3 & 2525 & 1370 \\
& $(1965-2715)$ & $(610-2050)$ \\
\hline 4 & 4215 & 2040 \\
& $(2260-4525)$ & $(910-3772)$ \\
\hline 5 & 7810 & 3710 \\
& $(7210-8185)$ & $(2320-5128)$ \\
\hline 6 & 8900 & 4000 \\
& $(8690-9090)$ & $(1840-6570)$ \\
\hline
\end{tabular}

Interquartile ranges in parentheses.

\section{Utility for gains and losses}

Figure 2 displays the elicited utility function based on the median data. The estimated parameters are given in Table 7 . The elicited utility function was not entirely consistent with the conjecture of Kahneman and Tversky (1979) that utility is S-shaped. For gains the function was concave. The median power coefficient of 0.86 differed significantly from 1 ( $p$ $=0.041)$ and was close and not significantly different from the power coefficients found in most previous studies. The interquartile range for the power coefficient indicated considerable variation at the individual level. 
Figure 2: The Elicited Utility Function Based on the Median Data

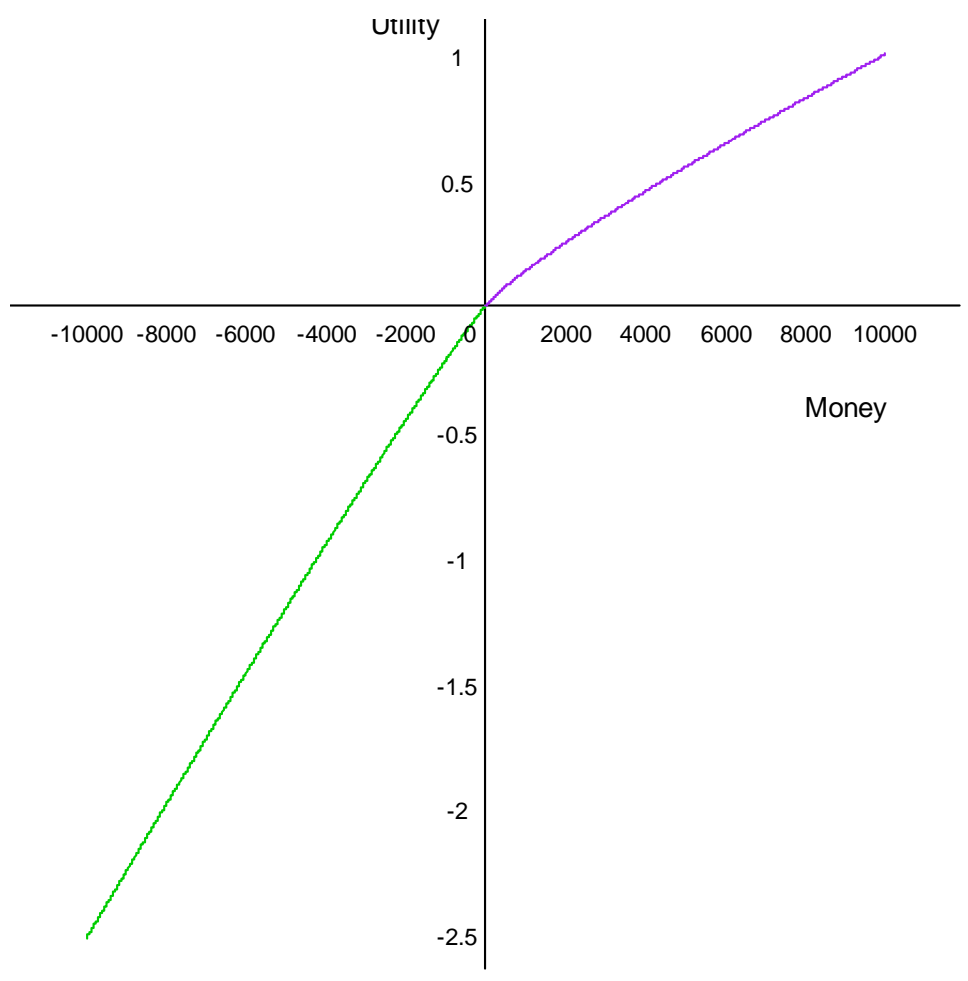

For losses, however, we did not observe convexity, but slight concavity. The median power estimate of 1.06 differed significantly from $1(\mathrm{p}=0.015)$. Our median estimate was also significantly different from the medians found in earlier studies that estimated the utility for losses $(\mathrm{p}<0.001)$.

Table 7: Estimation results

\begin{tabular}{lccc}
\hline & Power estimate gains & Power estimate losses & Loss aversion coefficient \\
Median & 0.86 & 1.06 & 2.61 \\
IQR & $0.66-1.08$ & $0.92-1.49$ & $1.51-5.51$ \\
\hline
\end{tabular}

IQR stands for interquartile range 
The individual estimates are displayed in Appendix C. Table 8 shows the classification of subjects based on their power estimates. The most common pattern was concave utility for gains and concave utility for losses. The proportion of subjects with an everywhere concave utility function was, however, not significantly different from the proportion of subjects with an S-shaped utility function $(\mathrm{p}=0.487)$. For gains, concave utility was clearly the dominant pattern and the proportion of concave subjects was significantly different from the proportion of convex subjects $(p=0.008)$. For losses, concave utility was also the most common pattern, but the proportion of concave subjects was not significantly different from the proportion of convex subjects $(p=0.243)$.

Table 8: Classification of subjects according to the shape of their utility function.

\begin{tabular}{|l|l|c|c|c|}
\hline \hline & & \multicolumn{3}{|c|}{ Losses } \\
\hline \hline \multirow{4}{*}{ Gains } & & Concave & Convex & Total \\
\cline { 2 - 5 } & Concave & 19 & 14 & 33 \\
\cline { 2 - 5 } & Convex & 9 & 5 & 14 \\
\cline { 2 - 5 } & Total & 28 & 19 & 47 \\
\hline \hline
\end{tabular}

It is of interest to compare the findings of Tables 6 and 8. In Table 6 we observed that for losses most subjects were risk seeking. In Table 8 we observed that most subjects had concave utility for losses. These findings illustrate that there is no one-to-one relationship between risk aversion and concave utility under prospect theory and that concave utility and risk seeking behavior can and in fact do occur simultaneously. These results provide empirical evidence for the theoretical results derived by Chateauneuf and Cohen (1994).

Loss aversion

We found clear evidence of loss aversion. Table 7 shows the results at the aggregate level. The median of the individual loss aversion coefficients differed significantly from $1(\mathrm{p}$ $=0.000)$, the case of no loss aversion. It was also significantly different from the findings of 
Tversky and Kahneman (1992) $(\mathrm{p}=0.029)$, but not from teh findings of Abdellaoui, Bleichrodt, and Paraschiv (forthcoming) $(\mathrm{p}=0.116)$. The interquartile range showed considerable variation at the individual level.

Loss aversion was clearly the dominant pattern at the individual level. Thirty-six subjects $(76.6 \%)$ had a median loss aversion coefficient that exceeded 1 and were classified as loss averse. Only 6 subjects had a median loss aversion coefficient less than 1 and were classified as gain seeking. For 5 subjects all loss aversion coefficients exceeded 10 and they were not classified. The proportion of loss averse subjects was significantly different from the proportion of gain seeking subjects $(\mathrm{p}=0.000)$. The support for loss aversion that we observed at the individual level is comparable with the findings of Abdellaoui, Bleichrodt, and Paraschiv (forthcoming).

\section{Probability weighting}

Recall that our estimation procedure also yielded some information on probability weighting. Table 9 summarizes our estimations. The table shows that our, admittedly limited, results were broadly consistent with inverse S-shaped probability weighting. For a probability of $1 / 3$ we observe no probability weighting for losses $(p=0.710)$. For probability $1 / 2$ there is small but significant underweighting of probability both for gains $(p=0.030)$ and for losses $(p=0.003)$. There is more pronounced underweighting of $2 / 3$ for gains $(p=0.000)$. The results were similar to those obtained in earlier studies. For example, Abdellaoui (2000) found that $\mathrm{w}^{-}(1 / 3)=0.35, \mathrm{w}^{-}(1 / 2)=0.46, \mathrm{w}^{+}(1 / 2)=0.39$, and $\mathrm{w}^{+}(2 / 3)=0.50$. Only $\mathrm{w}^{+}(1 / 2)$ differed significantly from Abdellaoui (2000) $(\mathrm{p}=0.006$, the other $\mathrm{p}$-values all exceeded 0.40$)$.

We could not reject the null hypothesis that $\mathrm{w}^{+}(1 / 2)=\mathrm{w}^{-}(1 / 2)(\mathrm{p}=0.35)$. Hence, we could not reject the hypothesis that the degree of probability weighting was the same for gains and for losses for a probability of $1 / 2$. 
Table 9: Results on probability weighting

\begin{tabular}{ccc}
\hline & Median & Interquartile range \\
$\mathrm{W}^{+}(1 / 2)$ & 0.46 & $0.36-0.54$ \\
$\mathrm{~W}^{+}(2 / 3)$ & 0.53 & $0.43-0.70$ \\
$\mathrm{~W}^{-}(1 / 3)$ & 0.34 & $0.25-0.42$ \\
$\mathrm{~W}^{-}(1 / 2)$ & 0.45 & $0.36-0.53$ \\
\hline
\end{tabular}

Comparison with expected utility

Table 10 shows the obtained power estimates under expected utility, i.e. when we assume that people do not transform probabilities. The table clearly illustrates that the existence of probability weighting implies that expected utility leads to distorted utilities. First, the power coefficients under expected utility were indeed generally different from those obtained under prospect theory. For gains, they are both significantly lower than under prospect theory $(p=0.041$ when probability $1 / 2$ was used in the elicitation and $p<0.001$ when probability $2 / 3$ was used in the elicitation) showing that expected utility overestimates the degree of concavity of utility for gains when subjects underweight probabilities. A second indication that expected utility leads to biased utilities is that the power coefficients for $\mathrm{p}_{\mathrm{g}}=$ $1 / 2$ and $p_{g}=2 / 3$ were significantly different $(p<0.001)$. The dependence of utility on the probability used in the elicitation entails another violation of expected utility.

Table 10: Power estimates under expected utility

\begin{tabular}{|l|c|c|c|c|}
\hline & \multicolumn{2}{|c|}{ Gains } & \multicolumn{2}{c|}{ Losses } \\
\hline & $\mathrm{p}_{\mathrm{g}}=1 / 2$ & $\mathrm{p}_{\mathrm{g}}=2 / 3$ & $\mathrm{p}_{\ell}=1 / 3$ & $\mathrm{p}_{\ell}=1 / 2$ \\
\hline Median & 0.80 & 0.53 & 1.06 & 0.90 \\
\hline IQR & $0.51-0.87$ & $0.42-0.73$ & $0.77-1.36$ & $0.80-1.25$ \\
\hline
\end{tabular}

IQR stands for interquartile range.

For losses, the power coefficient was significantly different from the power coefficient under prospect theory for probability $1 / 2(p=0.009)$ but not for probability $1 / 3(p=$ 
0.860). The power coefficients for $\mathrm{p}_{\ell}=1 / 3$ and $\mathrm{p}_{\ell}=1 / 2$ did not differ significantly $(\mathrm{p}=0.08)$.

That utility for losses under prospect theory did not differ significantly from utility under expected utility when the elicitation was performed with $\mathrm{p}_{\ell}=1 / 3$ is consistent with the observed absence of probability weighting for $\mathrm{p}_{\ell}=1 / 3$. A similar finding was reported by Abdellaoui, Barrios, and Wakker (2007). For $\mathrm{p}_{\ell}=1 / 2$ expected utility overestimated the degree of convexity of the utility for losses consistent with the observed underweighting of $1 / 2$. In fact, under expected utility the utility for losses was convex whereas under prospect theory it was slightly concave. This finding suggests that previous measurements that observed convex utility for losses and that typically used a probability of $1 / 2$ in the elicitations were biased towards convexity of utility.

\section{Discussion}

This paper has proposed a new and tractable method to measure utility and loss aversion under prospect theory. Because the method only uses certainty equivalents for twooutcome prospects, it is easy to implement in empirical research and in practical decision analysis. Analyzing the data by standard regression tools gives the coefficients for the utility function. We hope that the provision of such a tractable method will foster the use of prospect theory in applications.

Our experimental results were broadly consistent with the assumptions of prospect theory. We found concave utility for gains, strong evidence for loss aversion, and data on probability weighting which were consistent with inverse S-shaped probability weighting. Most of our findings were in line with those of previous studies on prospect theory. Under prospect theory, the results on utility were robust, in the sense that they were not sensitive to the probability used in the elicitation. This offers support for the validity of prospect theory. 
Finally, we observed that falsely assuming expected utility often leads to substantial biases in elicited utilities.

We observed a high degree of risk aversion for mixed 50-50 prospects. We observed only modest curvature of utility, both for gains and for losses, and little probability weighting of $1 / 2$ both for gains and for losses. Hence, the strong degree of risk aversion in 50-50 mixed prospects was caused by loss aversion. This finding also emphasizes that ignoring loss aversion in the measurement of utility will produce biased utilities.

In contrast with the assumptions of prospect theory and with the findings of earlier studies, we found no evidence of convex utility for losses. The utility for losses was slightly concave in our study whereas previous studies generally found slight convexity. Even though we found concave utility for losses, risk seeking was the dominant pattern for losses. This illustrates that the one-to-one relationship between utility curvature and risk attitude, which exists under expected utility, is no longer present under prospect theory.

Although the difference in the observed shape of utility for losses was relatively modest compared with previous studies that measured utility under prospect theory, it is worth reflecting why this difference may have occurred. One difference with earlier studies is that our elicitation was based on certainty equivalents whereas most previous studies used the trade-off method. It is, however, hard to see why the trade-off method would lead to more convexity. Tversky and Kahneman (1992) also elicited certainty equivalents but, as mentioned before, they imposed parametric assumptions about probability weighting.

Another difference with studies that used the trade-off method was that we imposed parametric assumptions for utility. It is possible that the outcome of the nonlinear least squares analysis was not unique but that there was a range of values for which the goodness of fit was broadly similar. For example, risk seeking for losses can both be explained by a less elevated probability weighting function and by convex utility for losses. We tested the 
results of our analysis by different statistical algorithms and found that the results were stable, however, suggesting that convergence problems and interactions between the parameters have not been driving the difference in findings.

Combining the available evidence from this and previous studies, it seems safe to conclude that the utility for losses is closer to linearity than the utility for gains and that curvature of utility for losses does not contribute much to observed risk attitudes. For all practical purposes, to take utility for losses linear does not seem to lead to substantial distortions. Of course, this conclusion only holds at the aggregate level. At the individual level the picture is much more diverse. For individual decisions, individual prospect theory parameters must be elicited. It is here that our method can prove particularly useful. 
Appendix A: Illustration of questions

Figure A-1: Illustration of a task in the gain domain
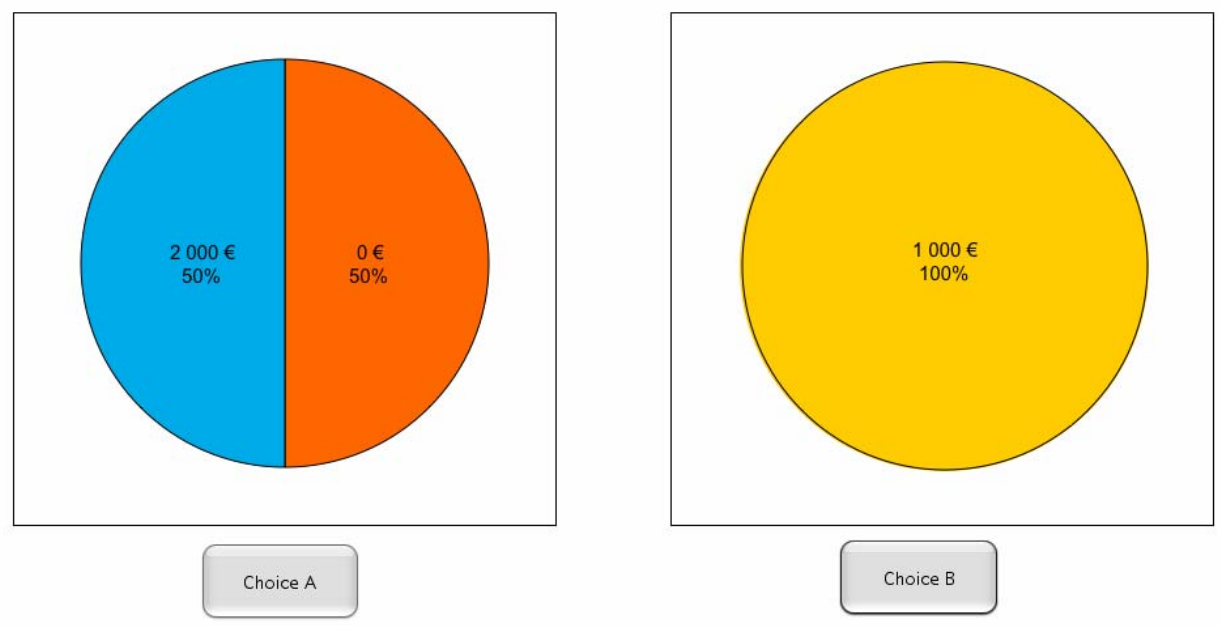

OK

Figure A-2: Illustration of a task in the mixed domain
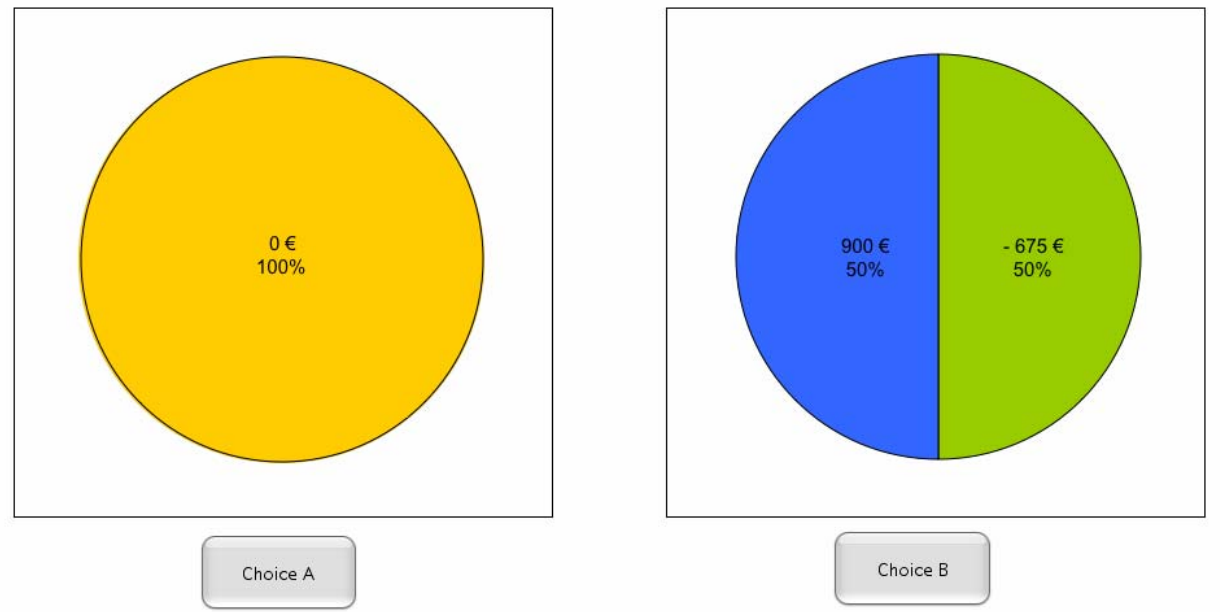


\section{Appendix B: Explanation of the bisection method}

The bisection method used to generate the iterations is illustrated in Table A1 for $\mathrm{L}_{1}$ for $\mathrm{p}_{\ell}=1 / 3$ and the elicitation of $\mathrm{L}_{6}^{*}$ for $\mathrm{p}_{\mathrm{g}}=\mathrm{p}_{\ell}=1 / 2$. The prospect that is chosen is printed in bold. Starting values in the iterations were always chosen so that prospects had equal expected value. Depending on the choice made, the certain outcome was increased or decreased. The size of the change was always half the size of the change in the previous question with the restriction that numbers should always be a multiple of 10 . When a number was not a multiple of 10 it was rounded downwards. The method resulted in an interval within which the indifference value should lie. The midpoint of this interval was taken as the indifference value. For example, in Table A1 the indifference value for $\mathrm{L}_{6}^{*}$ should lie between -3960 and -3680 . Then we took as the indifference value -3820 . In the elicitation of utility on the gains and loss domains, the certainty equivalents were elicited in five iterations. In the determination of the loss aversion coefficients, we used six iterations. We used one additional iteration in the determination of the loss aversion coefficients because the intervals $G_{j}^{*}-L_{j}^{*}$ were larger than the intervals $\left|\mathrm{x}_{\mathrm{j}}-\mathrm{y}_{\mathrm{j}}\right|$.

Table A1: An illustration of the bisection method.

\begin{tabular}{|c|c|c|}
\hline Iteration & Offered choices in elicitation of $\mathrm{L}_{1}$ & Offered choices in elicitation of $\mathrm{L}_{6}^{*}$ \\
\hline 1 & -660 vs. $(-2000, ; 0)$ & 0 vs. $(9090,1 / 2 ;-9090)$ \\
\hline 2 & -330 vs. $(-2000, ; 0)$ & 0 vs. $(9090,1 / 2 ;-4540)$ \\
\hline 3 & -490 vs. $(-2000, ; 0)$ & 0 vs. $(9090,1 / 2 ;-2270)$ \\
\hline 4 & -410 vs. $(-2000, ; 0)$ & 0 vs. $(9090,1 / 2 ;-3400)$ \\
\hline 5 & -450 vs. $(-2000, ; 0)$ & 0 vs. $(9090,1 / 2 ;-3960)$ \\
\hline 6 & & 0 vs. $(9090,1 / 2 ;-3680)$ \\
\hline Indifference value & -430 & -3820 \\
\hline
\end{tabular}


Appendix C: Overview of the individual results

\begin{tabular}{|c|c|c|c|}
\hline \multirow{2}{*}{ Subject } & \multicolumn{2}{|c|}{ Power function parameter } & \multirow{2}{*}{ Loss aversion } \\
\cline { 2 - 4 } & Gains & Losses & \\
\hline 1 & 1.12 & 0.68 & 1.67 \\
2 & 1.58 & 3.02 & 5.51 \\
3 & 0.77 & 0.91 & 2.16 \\
4 & 0.44 & 1.10 & 4.37 \\
5 & 0.78 & 1.63 & 1.15 \\
6 & 0.89 & 0.99 & 12.23 \\
7 & 0.27 & 1.28 & 11.83 \\
8 & 0.96 & 1.04 & 2.35 \\
9 & 1.66 & 0.95 & 0.86 \\
10 & 0.86 & 1.00 & 2.00 \\
11 & 1.10 & 1.28 & 0.47 \\
12 & 0.41 & 1.50 & Inf \\
13 & 1.00 & 1.00 & 0.77 \\
14 & 1.18 & 1.22 & 4.69 \\
15 & 0.45 & 0.76 & 4.37 \\
16 & 2.11 & 2.23 & 2.71 \\
17 & 0.83 & 0.92 & 1.32 \\
18 & 0.55 & 1.03 & 4.54 \\
19 & 0.71 & 1.12 & 6.02 \\
20 & 0.84 & 1.16 & 3.11 \\
21 & 1.69 & 1.07 & 0.39 \\
22 & 1.07 & 0.87 & 1.03 \\
23 & 0.72 & 0.93 & 1.76 \\
24 & 0.92 & 0.73 & 6.35 \\
25 & 1.32 & 1.26 & 9.51 \\
26 & 0.77 & 2.83 & Inf \\
27 & 0.73 & 0.81 & 1.73 \\
28 & 0.87 & 1.00 & 1.87 \\
29 & 0.45 & 1.75 & 24.21 \\
30 & 0.54 & 0.90 & 2.74 \\
31 & 0.80 & 2.84 & 2.35 \\
32 & 0.70 & 0.96 & 4.26 \\
33 & 0.61 & 1.10 & 7.47 \\
34 & 0.91 & 2.35 & 25.23 \\
35 & 1.58 & 0.91 & 0.34 \\
36 & 0.75 & 5.33 & Inf \\
37 & 0.99 & 0.92 & 0.99 \\
38 & 0.54 & 0.79 & 3.29 \\
39 & 2.06 & 0.96 & 1.44 \\
40 & 1.28 & 1.70 & 1.67 \\
41 & 0.42 & 1.12 & 7.00 \\
42 & 0.88 & 0.64 & 1.51 \\
43 & 0.91 & 1.49 & 2.52 \\
44 & 1.19 & 3.22 & Inf \\
45 & 0.96 & 1.55 & 3.05 \\
46 & 0.47 & 0.93 & \\
47 & 0.12 & 1.07 & Inf \\
\hline & & & \\
\hline
\end{tabular}




\section{References}

Abdellaoui, M. 2000. Parameter-free elicitation of utility and probability weighting functions. Management Science 46 1497-1512.

Abdellaoui, M., C. Barrios, P. P. Wakker. 2007. Reconciling introspective utility with revealed preference: Experimental arguments based on prospect theory. Journal of Econometrics 138 356-378.

Abdellaoui, M., H. Bleichrodt, C. Paraschiv. forthcoming. Measuring loss aversion under prospect theory: A parameter-free approach. Management Science

Abdellaoui, M., F. Vossmann, M. Weber. 2005. Choice-based elicitation and decomposition of decision weights for gains and losses under uncertainty. Management Science 51 1384-1399.

Baucells, M., F. H. Heukamp. 2006. Stochastic dominance and cumulative prospect theory. Management Science 52 1409-1423.

Baucells, M., A. Villasis. 2006. Stability of risk preferences and the reflection effect of prospect theory. Working Paper, IESE.

Benartzi, S., R. H. Thaler. 1995. Myopic loss aversion and the equity premium puzzle. Quarterly Journal of Economics 110 73-92.

Bleichrodt, H., J. M. Abellan, J. L. Pinto, I. Mendez. 2007. Resolving inconsistencies in utility measurement under risk: Tests of generalizations of expected utility. Management Science 53 469-482.

Bleichrodt, H., J. L. Pinto. 2000. A parameter-free elicitation of the probability weighting function in medical decision analysis. Management Science 46 1485-1496.

Bleichrodt, H., J. L. Pinto, P. P. Wakker. 2001. Making descriptive use of prospect theory to improve the prescriptive use of expected utility. Management Science 47 1498-1514.

Booij, A. S., G. van de Kuilen. 2006. A parameter-free analysis of the utility of money for the general population under prospect theory. Working Paper, University of Amsterdam.

Bostic, R., R. J. Herrnstein, R. D. Luce. 1990. The effect on the preference reversal of using choice indifferences. Journal of Economic Behavior and Organization 13 193-212.

Bowman, D., D. Minehart, M. Rabin. 1999. Loss aversion in a consumption-savings model. Journal of Economic Behavior and Organization 38 155-178.

Camerer, C. F., T.-H. Ho. 1994. Nonlinear weighting of probabilities and violations of the betweenness axiom. Journal of Risk and Uncertainty 8 167-196. 
Chateauneuf, A., M. Cohen. 1994. Risk seeking with diminishing marginal utility in a nonexpected utility model. Journal of Risk and Uncertainty 9 77-91.

Etchart-Vincent, N. 2004. Is probability weighting sensitive to the magnitude of consequences? An experimental investigation on losses. Journal of Risk and Uncertainty 28 217-235.

Farquhar, P. 1984. Utility assessment methods. Management Science 30 1283-1300.

Fennema, H., M. van Assen. 1998. Measuring the utility of losses by means of the trade-off method. Journal of Risk and Uncertainty 17 277-295.

Fishburn, P. C., G. A. Kochenberger. 1979. Two-piece von Neumann Morgenstern utility functions. Decision Sciences 10 503-518.

Gonzalez, R., G. Wu. 1999. On the form of the probability weighting function. Cognitive Psychology 38 129-166.

Heath, C., S. Huddart, M. Lang. 1999. Psychological factors and stock option exercise. Quarterly Journal of Economics 114 601-627.

Hershey, J. C., P. J. H. Schoemaker. 1985. Probability versus certainty equivalence methods in utility measurement: Are they equivalent? Management Science 31 1213-1231.

Kahneman, D., A. Tversky. 1979. Prospect theory: An analysis of decision under risk. Econometrica 47 263-291.

Köbberling, V., P. P. Wakker. 2005. An index of loss aversion. Journal of Economic Theory 122 119-131.

Laughhunn, D. J., J. W. Payne, R. Crum. 1980. Managerial risk preferences for below-target returns. Management Science 26 1238-1249.

McCord, M., R. de Neufville. 1986. Lottery equivalents: Reduction of the certainty effect problem in utility assessment. Management Science 32 56-60.

Myagkov, M., C. R. Plott. 1997. Exchange economies and loss exposure: Experiments exploring prospect theory and competitive equilibria in market environments. American Economic Review 87 801-828.

Neilson, W. S. 2002. Comparative risk sensitivity with reference-dependent preferences. Journal of Risk and Uncertainty 24 131-142.

Payne, J. W., D. J. Laughhunn, R. Crum. 1980. Translation of gambles and aspiration level effects in risky choice behavior. Management Science 26 1039-1060.

Payne, J. W., D. J. Laughhunn, R. Crum. 1981. Further tests of aspiration level effects in risky choice behavior. Management Science 27 953-958. 
Pennings, J. M. E., A. Smidts. 2003. The shape of utility functions and organizational behavior. Management Science 49 1251-1263.

Schmidt, U., S. Traub. 2002. An experimental test of loss aversion. Journal of Risk and Uncertainty 25 233-249.

Schmidt, U., H. Zank. 2005. What is loss aversion? Journal of Risk and Uncertainty 30 157167.

Schoemaker, P. J. H. 1990. Are risk-attitudes related across domains and response modes? Management Science 36 1451-1463.

Schunk, D., C. Betsch. 2006. Explaining heterogeneity in utility functions by individual differences in decision modes. Journal of Economic Psychology 27 386-401.

Shalev, J. 2000. Loss aversion equilibrium. International Journal of Game Theory $29269-$ 287.

Sneddon, R., R. D. Luce. 2001. Empirical comparisons of bilinear and nonbilinear utility theories. Organizational Behavior and Human Decision Processes 84 71-94.

Starmer, C. 2000. Developments in non-expected utility theory: The hunt for a descriptive theory of choice under risk. Journal of Economic Literature 28 332-382.

Stott, H. P. 2006. Cumulative prospect theory's functional menagerie. Journal of Risk and Uncertainty 32 101-130.

Tversky, A., C. Fox. 1995. Weighing risk and uncertainty. Psychological Review 102 269283.

Tversky, A., D. Kahneman. 1992. Advances in prospect theory: Cumulative representation of uncertainty. Journal of Risk and Uncertainty 5 297-323.

Wakker, P. P., D. Deneffe. 1996. Eliciting von Neumann-Morgenstern utilities when probabilities are distorted or unknown. Management Science 42 1131-1150.

Wakker, P. P., A. Tversky. 1993. An axiomatization of cumulative prospect theory. Journal of Risk and Uncertainty 7 147-176.

Wu, G., R. Gonzalez. 1996. Curvature of the probability weighting function. Management Science 42 1676-1690. 